\title{
Recordação de Eventos Pessoais: Memória Autobiográfica, Consciência e Julgamento ${ }^{1}$
}

\author{
Gustavo Gauer ${ }^{2}$ \\ Universidade Federal de Minas Gerais \\ William Barbosa Gomes \\ Universidade Federal do Rio Grande do Sul
}

\begin{abstract}
RESUMO - A recordação de eventos pessoais marcantes é acompanhada de julgamentos relativos ao evento recuperado (reflexivos) e ao ato de lembrar em si (heurísticos). O presente estudo teve por objetivo explorar relações e distinções entre esses tipos de julgamentos na atribuição de importância pessoal a eventos autobiográficos. Para tanto, solicitou-se a 208 estudantes universitários (170 mulheres) que recordassem um evento marcante de vida e respondessem a um Questionário de Memória Autobiográfica, composto de 16 escalas. Em uma análise de componentes principais, o primeiro agrupou 10 variáveis referentes a qualidades fenomenais e a modalidades de imaginação. Um segundo componente agrupou seis variáveis referentes a julgamentos reflexivos. A importância atribuída ao evento encontrou-se mais relacionada a julgamentos reflexivos por meio dos quais o indivíduo atribui características ao evento de forma retroativa do que a qualidades fenomenais da experiência imediata de lembrar.
\end{abstract}

Palavras-chave: memória autobiográfica; fenomenologia; julgamento.

\section{Recollecting Personal Events: Autobiographical Memory, Consciousness and Judgment}

\begin{abstract}
The recollection of remarkable autobiographical events is accompanied by judgments about the recovered event (reflexive) and about the act of recollecting itself (heuristic). This study aimed at exploring relations and distinctions between these kinds of judgments in the process of conveying personal relevance to autobiographical events. For such, 208 college students (170 women) were required to recollect a remarkable event of their lives and to fill a 16-item Autobiographical Memory Questionnaire. Based on a main components analysis, the first grouped 10 variables related to phenomenal qualities and imagery modalities. A second component comprised six variables related to reflexive judgments. The rated importance of the event was more closely related to reflexive judgments by which an individual retroactively ascribes properties to the event than to phenomenal qualities of the immediate recollection experience.
\end{abstract}

Keywords: autobiographical memory; phenomenology; judgment.

A recordação de eventos pessoais vividos no passado constitui a memória autobiográfica, a síntese e a referência de nossas histórias de vida. O ato de recordar envolve várias habilidades cognitivas, desde aquelas que permitem lembrar um fato pessoal, como o caminho de casa ao trabalho, até aquelas necessárias para escrever um livro contando a história de uma vida. Pesquisas em memória autobiográfica têm se dedicado ao estudo da recordação de eventos pessoais específicos, marcantes, contextualizados no tempo e no espaço (Brewer, 1986; Rubin, 1998). Como se sabe, dentre a miríade de eventos específicos que

$1 \mathrm{O}$ artigo deriva da tese de doutorado do primeiro autor. $\mathrm{O}$ trabalho contou com apoio financeiro do CNPq e da CAPES. Os autores agradecem ao Prof. David C. Rubin, da Duke University (Durham, NC); ao Prof. Marco Antônio Teixeira, da UFRGS (Porto Alegre, RS); à Profa. Carolina Lisboa, do Centro Universitário Feevale (Novo Hamburgo, RS); e aos bolsistas de iniciação científica do Curso de Psicologia da UFRGS, Luciano Alencastro e Carolina Tonial, pelo auxílio na coleta e análise de dados.

2 Endereço: Departamento de Psicologia, UFMG - FAFICH. Av. Antônio Carlos, 6627 sala F - 4050. Belo Horizonte, MG. CEP 31270-901. E-mail: gauerg@fafích.ufmg.br. acontecem ao longo de uma vida, nem todos ocasionam registros duradouros a ponto de serem lembrados a longo, ou longuíssimo prazo (Westbury \& Dennett, 2000). Outros, no entanto, são lembrados com facilidade, de forma vívida e detalhada, e com mais intensidade do que acontecimentos ocorridos inúmeras vezes.

A facilidade e a vivacidade da recordação correspondem ao conceito de disponibilidade de memórias (Johnson, Foley, Suengas \& Raye, 1988). Essas memórias altamente disponíveis têm sido operacionalizadas como eventos marcantes (Pillemer, 1998), episódios nucleares (McAdams, 1985), memórias definidoras do self (Singer \& Salovey, 1993), ou memórias vívidas (Thomsen \& Berntsen, 2003; Rubin \& Kozin, 1984). Trata-se de memórias importantes e duradouras, revividas com qualidades quase-sensoriais (Conway, 2001), e que serão referidas ao longo do presente trabalho como memórias de eventos marcantes. Os eventos que ocasionam tais memórias tornam-se marcos tanto na organização da trajetória individual (Elnick, Margrett, Fitzgerald \& Labouvie-Vief, 1999), quanto na compreensão da própria história de vida. Contudo, o que distingue um evento como marcante? $\mathrm{O}$ evento em si mesmo seria 
dotado de significado especial ou tal significado seria uma atribuição a posteriori?

Certamente, há eventos que já trazem em si a marca duradoura, mas há eventos que se tornam marcantes com o passar do tempo. De um modo ou de outro, o que está implícito na recuperação de eventos pessoais são as capacidades de memorizar eventos e de julgá-los reflexivamente. Essas questões foram inicialmente endereçadas por Brown e Kulik (2000), que investigaram o fenômeno referente a memórias vívidas e duradouras que as pessoas têm da situação em que ficaram sabendo de eventos públicos. Esse fenômeno tem sido abordado na literatura como memórias "em lampejo" (do inglês, flashbulb memories). Naquele trabalho, os autores propuseram um mecanismo de modulação que atuaria na fase de codificação da memória, ou seja, os fatores que farão um evento ser marcante estão presentes quando da sua ocorrência. Em contraste, Neisser (2000) ressaltou a importância dos processos posteriores e do contexto na atribuição de importância pessoal aos eventos. Em um desenvolvimento posterior, Rubin e Kozin (1984) revisaram o fenômeno, estendendo o alcance da explicação a eventos pessoais e postulando o conceito mais abrangente de memórias vívidas.

No âmbito do desenvolvimento, memórias de eventos marcantes proporcionam lições e insights à composição da história de vida (Thorne, McLean \& Lawrence, 2004). A modelagem da memória autobiográfica integra-se com a compreensão das diversas etapas ao longo do ciclo de vida, relacionando-se, por exemplo, com o final da amnésia infantil (Rubin, 2000), com o desenvolvimento da identidade na adolescência e adultez jovem (Rubin, Rahhal \& Poon, 1998), e com o envelhecimento bem-sucedido (Wong \& Watt, 1991). Nesse sentido, memórias de eventos marcantes constituem marcos determinantes na organização da história de vida do indivíduo. Elas permitem ao sujeito definir a si mesmo, se reconhecer na sua própria experiência e se expressar a respeito da sua trajetória singular (Blagov \& Singer, 2004). Essas memórias refletem padrões de expectativas culturais permitindo ao indivíduo verificar a maior ou menor adequação da sua própria trajetória individual às convenções sociais de quais são os eventos que tipicamente fazem parte de uma história de vida (Berntsen \& Rubin, 2004).

A recuperação de um evento na memória ocorre por meio de pistas atuais que levam a uma busca ativa da informação em um banco de dados armazenado em longo prazo. Desse modo, a recuperação é gerativa (Conway \& Pleydell-Pearce, 2000), pois o conhecimento autobiográfico pode ser modificado se a informação entra em desacordo com as demandas e metas atuais. As eventuais modificações da informação autobiográfica, concomitantes ao processo de recuperação, podem estar relacionadas a processos de julgamento pelos quais o indivíduo atribui propriedades aos eventos passados, os avalia e reavalia reflexivamente, modificando os seus significados (Neisser, 2000).

O processo de recordação de eventos pessoais caracteriza-se por uma série de qualidades e processos amplamente documentados na literatura e vivenciados no nosso dia-a-dia. As recordações podem vir em forma narrativa (Greenberg \& Rubin, 2003), acompanhadas de emoções ligadas ao evento original (McGaugh, 2003; Schaefer \& Philippot, 2005) e de imagens vívidas em múltiplas modalidades sensoriais (Rubin \& Kozin, 1984). Os sentimentos fenomenais de reviver o acontecimento original levam aquele que recorda de volta ao tempo em que o evento ocorreu (Tulving, 1983; Wheeler, Stuss \& Tulving, 1997). Esses processos acompanham a capacidade e a experiência de recordar de maneira imediata, isto é, tomar consciência. A recordação de eventos pessoais é também uma avaliação do que se está lembrando e do ato de lembrar em si, por meio de uma série de julgamentos, que variam do pré-reflexivo ao reflexivo.

Os julgamentos pré-reflexivos ou heurísticos ocorrem de forma instantânea e se baseiam em informações da própria representação, como a vivacidade das imagens. Tais julgamentos permitem o monitoramento de realidade (real ou imaginária) e de fonte (interna ou externa) das representações na consciência (Johnson \& cols., 1988; Johnson, Hashtroudi \& Lindsay, 1993). Nesse caso, o que é julgado ou avaliado é o processo de recordação em si, e as informações que embasam esse julgamento são as qualidades fenomenais da própria recordação. Os julgamentos heurísticos de realidade e fonte relacionam-se aos sensos de reexperiência, orientação para o passado e saber/lembrar, típicos da recordação consciente. Eles são considerados subsidiários da fluência de informação de origem senso-perceptiva e contextual que, quando da recordação, ocasionam a produção de imagens visuais, acústicas, e a reinstalação de emoções.

Nos julgamentos reflexivos (Talarico \& Rubin, 2003) ou metacognitivos (Rubin \& Siegler, 2004) o ato de conhecer volta-se a si mesmo e ao próprio conhecimento (Ferrater Mora, 1979) para atribuição de significado. Entre esses atributos incluem-se: a avaliação da importância do evento para a vida pessoal; a estimativa de quando ocorreu e de quantas vezes se pensou ou falou sobre ele; a indicação de quão específica é a memória; o levantamento das conseqüências pessoais que o evento acarretou, entre outras propriedades (Thomsen \& Berntsen, 2003).

Recentemente, Rubin, Schrauf e Greenberg (2003) operacionalizaram a memória autobiográfica em três processos componentes que podem ser denominados de: (1) recordação e crença, (2) modalidades sensoriais de imaginação, e (3) propriedades atribuídas a eventos. A recordação e a crença estão presentes nas qualidades do estado subjetivo que acompanham os eventos únicos do passado: senso de reviver e de viajar de volta ao tempo do evento original, senso de que o evento de fato aconteceu como ele é lembrado (dito de outra forma, crença na acuidade da memória) e senso de lembrar do evento ao invés de apenas saber que ele aconteceu (julgamento de lembrar ou saber).

As modalidades sensoriais de imaginação reaparecem na linguagem e na revivência das emoções. Os eventos podem ser lembrados em palavras, em imagens e em narrativas, seja em histórias coerentes ou em fragmentos desorganizados dos acontecimentos. Ademais, a recordação autobiográfica traz com maior ou menor força as emoções que o sujeito experimentou quando do evento original.

As propriedades atribuídas aos eventos caracterizam a relevância da memória: (1) importância pessoal que o sujeito atribui ao evento; (2) freqüência com que o evento foi ensaiado (tanto em pensamento quanto em conversação interpessoal); (3) especificidade do evento (se ele foi único 
no espaço e tempo, estendido por um período mais longo, ou se ele trata de uma mescla ou resumo de eventos parecidos) (Rubin \& cols., 2003); e (4) idade do evento (a estimação pelo sujeito da data em que o evento ocorreu). Como se pode notar, os dois primeiros componentes referem-se a processos pré-reflexivos e o terceiro componente a processos reflexivos e servem para esclarecer a diferença entre recordações com maior ou menor importância.

A relação das qualidades fenomenais com outras propriedades - neurais, comportamentais e computacionais - de processos cognitivos apenas recentemente vem ocupando espaço na literatura (Jack \& Roepstorff, 2002) e grande parte do desenvolvimento atual dessa abordagem deve-se aos estudos em memória autobiográfica. Isso ocorre pela própria definição do conceito, calcada na presença do estado consciente de recordação, além dos processos básicos das capacidades de memória - codificação, armazenamento e recuperação.

Na verdade, julgamentos reflexivos de propriedades de eventos encontram amparo para além dos estudos em psicologia cognitiva. Evidências neurocognitivas apontam para a intensidade emocional como fator que torna memórias vívidas de eventos emocionais altamente disponíveis à recordação (McGaugh, 2003). A intensidade emocional, relacionada à ativação de circuitos da amídala e hipocampo e à liberação de hormônios ligados ao estresse - cortisol e noradrenalina - tem sido apontada como aspecto central na formação e recuperação de memórias autobiográficas em geral e das marcantes em especial. No modelo proposto por Damasio (1994), forma-se uma representação “topográfica" da experiência pessoal, na qual alguns eventos - os mais estreitamente ligados a emoções - se destacam no relevo. Dessa maneira, a aquisição e a recuperação de eventos emocionais podem ser otimizadas ou prejudicadas pela presença de sentimentos. São esses sentimentos que provocam a evitação de eventos potencialmente ligados a sentimentos negativos e a procura por situações que podem trazer sentimentos positivos. Mesmo que os julgamentos que diferenciam eventos negativos sejam marcadamente reflexivos, provavelmente eles são influenciados pela intensidade emocional como um processo neurofisiológico básico. De fato, a combinação dos dados de neuroimagem com os achados em psicologia cognitiva, como aqueles apresentados neste trabalho, pode contribuir para uma compreensão abrangente da memória autobiográfica, seus processos e produtos. A memória autobiográfica poderá, então, ser entendida como um tipo especial de articulação de memória, emoção e julgamento. Essa articulação é o que propicia a nós conhecermos o mundo e a nós mesmos, e nos apropriarmos de nossa experiência de uma maneira aparentemente singular na natureza.

A análise da recuperação de eventos pessoais, operacionalizada em processos componentes, tem sido realizada por meio do Questionário de Memória Autobiográfica (QMA). O instrumento foi desenvolvido por Rubin e cols. (2003) e tem sido usado de forma exploratória com número variável de itens. A temática dos itens é derivada da literatura teórica em memória autobiográfica e caracterizam a capacidade de recordar eventos pessoais específicos. Talarico e Rubin (2004) utilizaram o QMA para explorar a vivacidade das memórias que indivíduos tinham da notícia dos atentados terroristas de 11 de setembro de 2001, após diferentes intervalos de tempo, constatando que a característica principal dessas memórias que se preservava em longo prazo era a confiança na acuidade da memória em relação ao evento. Em outro estudo, Rubin e cols. (2003) encontraram relações entre humor negativo e decréscimos tanto na coerência das memórias, quanto no grau em que o indivíduo confia nelas. Nesse estudo, realizou-se uma análise fatorial, na qual os itens agruparam-se em um grande fator comum.

Os itens do QMA se mostraram sensíveis a variações nas condições de aquisição e consolidação de memórias autobiográficas públicas e pessoais, sem procurar, contudo, a distinção entre os julgamentos pré-reflexivos e reflexivos na recordação. O presente estudo ocupa-se da distinção entre julgamentos pré-reflexivos e reflexivos na recordação de eventos pessoais altamente relevantes. Especificamente, a análise procurou verificar a hipótese de que os itens referentes a propriedades atribuídas diferenciam-se dos outros itens do questionário, visto que tais propriedades são atribuídas mediante julgamentos reflexivos, distintos dos julgamentos heurísticos das qualidades de recordação e dos processos cognitivos pré-reflexivos como a imaginação.

\section{Participantes}

\section{Método}

Participaram deste estudo 208 estudantes universitários de vários cursos, sendo 170 mulheres $(80,18 \%)$. A idade média foi de 22,36 anos ( $\mathrm{DP}=6,17)$. Todos os participantes estavam matriculados em disciplinas de História da Psicologia e Psicologia Geral em duas universidades, uma pública e uma particular, situadas na Região Metropolitana de Porto Alegre.

\section{Instrumento e procedimento}

$\mathrm{O}$ instrumento utilizado constou de três partes. Na primeira, solicitava-se ao participante que recordasse um evento marcante de sua vida. Na segunda parte, o participante respondia a uma versão do Questionário de Memória Autobiográfica (QMA), modificado especialmente para este estudo. $\mathrm{O}$ QMA estava constituído de 16 itens, os quais consistiam em uma afirmativa sobre a lembrança que o indivíduo evocou, seguida de uma escala Likert de l a 7. Exemplos de itens são: Lembrando o episódio, eu posso vê-lo na minha mente (analisado como a variável Vê - imaginação visual); Lembrando o episódio, ele me vem em palavras (variável Em Palavras linguagem); e Desde que aconteceu, eu conversei com alguém sobre este episódio (variável Falei - ensaio manifesto). $\mathrm{Na}$ terceira parte, solicitava-se que o participante estimasse a data em que o evento aconteceu e a especificidade da memória. A questão sobre especificidade perguntava "Até onde você sabe, esta memória corresponde a", com três alternativas de resposta: (a) um evento que aconteceu uma única vez num tempo e lugar particulares; (b) um resumo ou mescla de vários eventos parecidos; e (c) eventos que ocorreram ao longo de um período de tempo, que durou mais que um dia. Para os fins deste estudo, a idade do evento e a sua especificidade 
foram focalizadas em análises descritivas, enquanto que as escalas de qualidades fenomenais e julgamentos do QMA passaram por um procedimento exploratório de análise de componentes principais.

Os dados foram coletados em sala de aula mediante entendimento com os professores responsáveis pelas disciplinas. Os participantes eram convidados a tomar parte em um estudo sobre memória humana, e o pesquisador explicava brevemente que a atividade envolvia a lembrança de eventos ou de episódios pessoais. O pesquisador esclarecia que um evento pessoal é um acontecimento único, bem contextualizado num tempo e lugar específicos, e apresentava os tipos de questões e escalas que compunham o questionário. Dois participantes potenciais declinaram de tomar parte no estudo.

\section{Resultados e Discussão}

\section{Tempo e especificidade nas memórias de eventos marcantes}

O tempo médio decorrido entre a data estimada do evento e o dia em que os dados foram coletados foi de 63 meses, em torno de cinco anos ou, mais precisamente, 1980 dias ( $\mathrm{DP}=2.615,97$ dias). A variabilidade foi alta em virtude da liberdade de contexto que a tarefa proporcionava. Não foi colocada nenhuma restrição quanto a tempo, lugar ou tema do evento a ser recordado. Combinando esse resultado com a idade média dos participantes quando da coleta dos dados, de 22,36 anos, seria possível inferir que os adultos jovens participantes da pesquisa tenderam a escolher eventos ocorridos na adolescência, em redor dos 17 anos de idade. Esse resultado concorda com dados sobre a distribuição de memórias autobiográficas ao longo do ciclo vital (Rubin \& cols., 1998; Rubin \& Schulkind, 1997). Esses estudos mostraram que a maior concentração de memórias autobiográficas, em qualquer idade, e principalmente na velhice, refere-se à época em que o sujeito tinha entre 10 e 30 anos de idade. Rubin e Schulkind chamam esse fenômeno de "lombada de reminiscência" (do inglês, reminiscence bump), visto que as curvas de distribuição de memórias ao longo do tempo geralmente apresentam um padrão de "lombada" ao redor das idades entre 10 e 30 anos, quando graficamente representadas. Embora ainda não exista uma teoria unânime, as hipóteses atualmente aceitas indicam uma influência do desenvolvimento da identidade que encontra uma fase crítica no período correspondente à lombada.

Das memórias evocadas, 69\% se referiram a eventos únicos ocorridos em tempo e lugar particulares, como solicitado pelo instrumento. Contudo, 23,3\% trouxeram eventos que se desenrolaram ao longo de um período de tempo maior que um dia, e 7,6\% trouxeram uma mescla de vários eventos parecidos. Os eventos marcantes ocorridos em períodos estendidos traziam relatos de viagens, experiências prolongadas em outro lugar, mudanças de cidade etc.

\section{Análise fatorial das escalas do QMA}

A análise de componentes principais, realizada com os itens do Questionário de Memória Autobiográfica, é apre- sentada na Tabela 1. As variáveis do QMA agruparam-se em dois componentes principais. O modelo apresenta um bom coeficiente de adequação dos dados à análise $(K M O=0,807)$, e os dois componentes explicaram cumulativamente $43,85 \%$ da variância.

O Componente 1, que explicou 32,06\% da variância no modelo (eigenvalue $=5,129$ ), agrupou 10 variáveis com cargas fatoriais acima de 0,45: Revive, De volta, Real, Lembra, Vê, Ouve, Cenário, Emoções, Em palavras e História. O Componente 2, explicando $11,79 \%$ da variância (eigenvalue $=1,887$ ), agrupou seis variáveis: Importante, Pensei, Falei, Evento Emocional, Conseqüências e Incomum. Para cada um dos conjuntos de escalas assim agrupados foi calculado o coeficiente de consistência interna: o Componente 1 apresentou $\alpha=0,837$, enquanto que o Componente 2 teve $\alpha=0,701$.

A estrutura fatorial não apontou para um conjunto equivalente às dimensões do modelo de processos componentes, pelo qual se poderia esperar três componentes. No entanto, no primeiro fator permaneceram todos os itens correspondentes às qualidades fenomenais da recordação senso de revivência, viagem de volta ao tempo do evento, crença na realidade do evento, e lembrar (julgamento de lembrar vs. saber) - e das modalidades sensoriais da imaginação - imaginação visual, auditiva e contextual/ espacial; emoção; linguagem; e narrativa. O Componente 1 foi denominado de processos de recordação por incluir os julgamentos experienciais pré-reflexivos.

O segundo fator reuniu os itens: Importante, Pensei, Falei, Evento Emocional, Conseqüências e Incomum. Esses itens relacionam-se em conjunto a avaliações que se faz sobre o evento e não mais ao ato de lembrar dele. Entende-se que essas avaliações atribuem significado pessoal ao evento, e que a principal característica delas é resultarem de processos de julgamentos reflexivos. A reflexividade, nesse caso, constitui o critério do julgamento na medida em que, para atribuir a intenção de uma determinada qualidade ao evento (por exemplo, atribuir a ele mais ou menos conseqüências pessoais), é necessário um retorno do sujeito a si mesmo e ao que é acessível de sua experiência. Em outras palavras, a avaliação de um evento ocorreria em comparação com os demais eventos no "repertório" da experiência. Essa hipótese aproxima tais processos de julgamento aos estudos sobre recuperação gerativa (Conway \& Pleydell-Pearce, 2000). O Componente 2 foi denominado de julgamentos reflexivos.

A estrutura fatorial encontrada diferiu da análise de Rubin e cols. (2003), em que todos os itens agruparam-se em um único componente. É preciso ressaltar duas diferenças entre os estudos. Primeiro, esses autores coletaram 30 eventos autobiográficos que cada participante recordou independentemente da sua importância pessoal. Em contraste, o presente estudo solicitou que se evocasse apenas uma tarefa. Todavia, tal diferença não parece ter interferido na estrutura fatorial que encontramos. Na verdade, o efeito esperado seria o oposto, visto que deveria haver menor variabilidade de escores de julgamentos de importância, diferenciando menos os eventos. A segunda mudança, que parece ter maior influência sobre os resultados, foi o acréscimo aos itens de propriedades atribuídas a eventos - conseqüências pessoais do evento, ensaio repetido desdobrado em privado e mani- 
Tabela 1. Análise de componentes principais dos itens do Questionário de Memória Autobiográfica (QMA) para eventos marcantes.

\begin{tabular}{|c|c|c|c|}
\hline \multirow{3}{*}{ Escalas do QMA } & \multirow{3}{*}{ Variável analisada } & \multicolumn{2}{|c|}{ Carga fatorial } \\
\hline & & \multicolumn{2}{|c|}{ Componente } \\
\hline & & $\begin{array}{l}1 \text { - Processos de } \\
\text { recordação }\end{array}$ & $\begin{array}{c}2 \text { - Julgamentos } \\
\text { reflexivos }\end{array}$ \\
\hline De volta & Senso de viajar de volta no tempo & 0,75 & 0,15 \\
\hline Revive & Senso de revivência & 0,70 & 0,24 \\
\hline Cenário & Imaginação do cenário contexto & 0,68 & $-0,13$ \\
\hline Emoções & Revivência de emoções do evento & 0,67 & 0,20 \\
\hline Ouve & Imaginação auditiva & 0,65 & 0,30 \\
\hline Lembra & Lembrar versus saber & 0,64 & 0,08 \\
\hline Vê & Imaginação visual & 0,60 & 0,11 \\
\hline Em palavras & Lembrar em palavras - linguagem & 0,58 & 0,32 \\
\hline História & História coerente - narrativa & 0,49 & 0,33 \\
\hline Real & Evento realmente aconteceu & 0,46 & $-0,09$ \\
\hline Conseqüências & Conseqüências pessoais do evento & 0,09 & 0,73 \\
\hline Evento emocional & Evento emocionalmente intenso & 0,20 & 0,72 \\
\hline Pensei & Ensaio privado & 0,31 & 0,65 \\
\hline Falei & Ensaio manifesto & 0,00 & 0,60 \\
\hline Importante & Importância pessoal do evento & 0,28 & 0,59 \\
\hline Incomum & Evento incomum & $-0,05$ & 0,49 \\
\hline
\end{tabular}

festo, caráter incomum do evento e intensidade emocional do evento - das escalas de características de memórias em lampejo propostas por Thomsen e Berntsen (2003). Essas escalas são referentes a julgamentos distintamente reflexivos e referentes ao evento, mais do que ao ato de recordar. Essa manipulação do instrumento deve ter colaborado criticamente para agrupar as variáveis em dois componentes bem definidos, distinguindo-se marcadamente o conjunto de julgamentos reflexivos.

\section{Considerações Finais}

É importante ressaltar que o tema aqui tratado encontra-se numa etapa inicial de teorização. Em um plano mais geral, trata-se do estabelecimento de relações entre memória, consciência, emoção e julgamento, a partir de um tipo específico de fenômeno, a lembrança de eventos importantes, por meio de uma metodologia que já foi definida como fenomenologia experimental (Johnson \& cols., 1988; Gauer \& Gomes, 2008). A tarefa utilizada constou de eventos marcantes lembrados sem qualquer restrição de contexto, como recordação livre (free recall). Dessa forma, a tarefa de recordação de evento marcante enfatizou o processo e os possíveis critérios de julgamento que levam o sujeito a eleger um evento como representativo, ou significativo da sua experiência. A diferença principal é que o conjunto dos resultados aqui apresentados parece apontar para uma articulação entre as variáveis de julgamento que caracterizam o fenômeno de memórias vívidas - importância e intensidade emocional 
do evento, ensaio repetido, conseqüências pessoais, e caráter incomum do evento - e a vivacidade da experiência fenomenal, como determinantes da atribuição de relevância pessoal a um evento.

Os julgamentos reflexivos que foram objeto de análise não correspondem diretamente àqueles raciocínios existenciais pelos quais se atribui significados simbólicos, como diretivas de memória que guiam o comportamento e as decisões no presente a partir da sabedoria do passado (Pillemer, 1998). Tampouco se trata dos julgamentos heurísticos, quase automáticos, que caracterizam o monitoramento de fonte e que nos permitem discernir memórias de fantasias (Johnson $\&$ cols., 1993). Com base nos dados deste e outros estudos, é possível antecipar que na capacidade de lembrar eventos marcantes haja três tipos de julgamentos em jogo, heurísticos, sistemáticos ou reflexivos e diretrizes de memória. Em ordem crescente de reflexividade, pode-se enumerar que: (1) os julgamentos heurísticos me permitem confiar que meu estado de consciência se trata de uma memória de um evento autobiográfico que realmente aconteceu; (2) os julgamentos reflexivos me permitem julgar se um evento autobiográfico do qual eu estou lembrando é relevante para mim mesmo em comparação com outros eventos; e (3) as diretivas de memória me permitem atribuir um profundo significado existencial a um evento autobiográfico que marcou minha vida. Ainda nesse sentido, pode-se ressaltar a forte interação entre esses julgamentos - importância pessoal, ensaio, conseqüências, raridade e intensidade emocional -, indicada pelos resultados aqui apresentados. Essa interação de propriedades atribuídas a eventos, primeiramente indicada por Brown e Kulik (2000), encontra-se reforçada por dados de recentes estudos psicológicos (Thomsen \& Berntsen, 2003) e neuropsicológicos (McGaugh, 2003).

Os resultados aqui apresentados também podem ser interpretados como um acréscimo ao modelo do monitoramento de fonte (Johnson \& cols., 1993). Naquele modelo, os julgamentos heurísticos dão conta da realidade e da fonte da memória, permitindo a um indivíduo decidir se um evento é real ou imaginário e se foi diretamente percebido de maneira testemunhal ou indiretamente recebido na forma de notícia. Por seu turno, os julgamentos reflexivos permitem ao sujeito decidir se aquele evento é importante na sua vida, ou seja, se é veículo de um conhecimento que ele pode ter de situações em seu próprio passado que podem guiar suas ações e decisões no contexto presente.

Este trabalho aplicou o modelo de processos componentes, mas paralelamente manteve atenção ao modelo de monitoramento de fonte. O modelo de monitoramento de fonte trata da relação entre vivacidade fenomenal e julgamentos heurísticos sobre a realidade e fonte das imagens apresentadas à consciência. O modelo de processos componentes, articulado às características de memórias vívidas, dá um passo adiante no sentido de explorar também os julgamentos reflexivos, que estão, como se verifica nos resultados dos estudos apresentados, altamente relacionados à lembrança de eventos marcantes, $\mathrm{O}$ tipo de evento marcante aqui escrutado é lembrado vividamente a ponto de podermos revivê-lo em suas emoções e sensações originais, trazendo aspectos significativos das nossas histórias de vida. Esse evento é representativo e prontamente escolhido quando nos pedem para lembrar um evento em especial de qualquer época de nossa vida, referente a qualquer assunto e ocorrido em qualquer contexto.

Os achados não desmentem o argumento (Thorne, 2000) de que não há uma memória primordial, ou um conjunto central de memórias importantes, e sim que escolhemos de um repertório relativamente grande de eventos passíveis de serem relatados e que podem mudar de um contexto para outro. Na verdade, a ênfase nos julgamentos de memórias vívidas depõe exatamente nesse sentido, de elucidar o processo de escolha a partir da consideração da interação de possíveis critérios que determinam a escolha de um ou outro evento numa dada situação, em resposta a determinada tarefa.

Julgamentos relacionados à relevância pessoal dos eventos autobiográficos, diferentemente de outros atributos, não parecem estar acoplados às qualidades fenomenais da memória do evento no momento em que ela é recuperada. De fato, esses julgamentos parecem agrupar-se em torno de outro aspecto da recordação, que pode ser o significado pessoal do evento. Esse significado seria atribuído de forma reflexiva, ou seja, julgado numa condição em que o sujeito volta-se para si mesmo (Ferrater Mora, 1979). O si mesmo é constituído pelos próprios eventos que perfizeram a sua experiência individual - sua autobiografia -, e também pelo contexto atual das condições em que está recuperando, em consonância com o modelo de recuperação gerativa de Conway e Pleydell-Pearce (2000). A questão é que, nesse processo, a reavaliação é possível em cada uma das ocasiões em que um evento é recordado. Por um lado, novas experiências reorganizam a história de vida na atualização dos significados de eventos. Por outro lado, as avaliações de novos eventos que vão se sucedendo e os planos e metas que direcionam o comportamento vão sendo demarcados pelo conhecimento autobiográfico.

A relevância prática dos dados referentes a propriedades atribuídas a eventos autobiográficos por meio de julgamentos reflexivos estende-se aos contextos do desenvolvimento humano e dos tratamentos psicológicos. Acerca deste último, os achados deste estudo aproximam-se de um entendimento do processo de ressignifícação da experiência. Interessa daqui por diante identificar mais precisamente os processos pelos quais um evento é dotado de significado durante a recordação, ressaltando-se o caráter presente, porém reflexivo, desses julgamentos. Abre-se caminho para questionar, do ponto de vista cognitivo, como acontecem as avaliações e reavaliações dos eventos relevantes em nossas histórias de vida. Em outras palavras, como atribuímos significados a esses acontecimentos, o que influencia a avaliação, e que fatores influenciam a modificação dessas avaliações, e conseqüentemente, a ressignifícação dos eventos pessoais. Cabe abrir frentes de investigação sobre esses aspectos da memória autobiográfica por sua relevância para contextos de desenvolvimento psicológico e psicoterapia.

Brown e Kulik (2000) propuseram um mecanismo diferenciado na ocasião da aquisição de memórias vívidas de eventos públicos (flashbulb memories), apelidado de "agora imprima!" (now print!). O modelo prevê o encadeamento de processos de reconhecimento de um evento como ines- 
perado, seguido de um teste de significado biológico individual que, se positivo, provoca um registro permanente do evento inesperado em si e dos eventos cerebrais recentes - daí a lembrança detalhada das circunstâncias pelo sujeito. Por outro lado, a consolidação se reforçaria por conta da alta freqüência de ensaio público e privado (falar e pensar sobre o evento), o que levaria o sujeito a percebê-lo como pleno de conseqüências, diretas e indiretas, para a sua vida. $\mathrm{O}$ modelo now print foi amplamente criticado e revisto, especialmente no que tange à relação entre importância do evento, conseqüências percebidas e ensaio repetido (Neisser, 2000), e à existência de um mecanismo especial para tais memórias (McCloskey, Wible \& Cohen, 1988; Rubin \& Kozin, 1984). Neisser argumenta que o ponto central é que essas memórias formarão registros vívidos e duradouros de eventos notáveis, cuja significância é atribuída a posteriori. Por outro lado, argumentos têm sido apresentados a favor de um mecanismo neurocognitivo específico que faz com que algumas memórias, no caso aquelas adquiridas no contexto de eventos estressantes ou altamente emocionais, formem registros vívidos e duradouros, sem que necessariamente tenham que ser ensaiadas repetidamente (McGaugh, 2003). Nesse modelo, em consonância com o proposto por Damásio (1994), a emoção vivida no evento ativa circuitos neurais regiões hipocampais e para-hipocampais, amídala e estruturas pré-frontais (Greenberg \& cols., 2005) - e processos hormonais (liberação de noradrenalina e cortisol) que modulam a aquisição e a consolidação. Como resultado é gerada uma memória mais vívida e duradoura que outras. Essa hipótese não implica em uma diferença na essência entre memórias em lampejo e as outras, mas sim em um contínuo em que a modulação de processos neurocognitivos faz se situarem as memórias de experiências pessoais.

\section{Referências}

Berntsen, D. \& Rubin, D. C. (2004). Cultural life scripts structure recall from autobiographical memory. Memory \& Cognition, 32, 427-442.

Blagov, P. S. \& Singer, J. A. (2004). Four dimensions of selfdefining memories (specificity, meaning, content, and affect) and their relationships to self-restraint, distress, and repressive defensiveness. Journal of Personality, 72, 481-512.

Brewer, W. F. (1986). What is autobiographical memory? Em D. C. Rubin (Ed.), Autobiographical memory (pp. 25-49). Cambridge: Cambridge University Press.

Brown, R. \& Kulik, J. (2000). Flashbulb memories. Em U. Neisser \& I. E. Hyman (Eds.), Memory observed: Remembering in natural contexts (pp. 50-65). New York: Worth Publishers.

Conway, M. A. (2001). Phenomenological records and the selfmemory system. Em C. Hoerl \& T. McCormack (Eds.), Time and memory: Issues in philosophy and psychology (pp.235-255). Oxford: Oxford University Press.

Conway, M. A. \& Pleydell-Pearce, C. W. (2000). The construction of autobiographical memories in the self-memory system. Psychological Review, 107, 261-288.

Damasio, A. R. (1994). Descartes'error: Emotion, reason, and the human brain. New York: Avon.
Elnick, A. B., Margrett, J. A., Fitzgerald, J. M. \& Labouvie-Vief, G. (1999). Benchmark memories in adulthood: Central domains and predictors of their frequency. Journal of Adult Development, 6, 45-57.

Ferrater Mora, J. (1979). Diccionario de filosofía. Madrid: Alianza Editorial.

Gauer, G. \& Gomes, W. B. (2008). Recordação autobiográfica: reconsiderando dados fenomenais e correlatos neurais. Aletheia (Canoas), 27, 51-64.

Greenberg, D. L. \& Rubin, D. C. (2003). The neuropsychology of autobiographical memory. Cortex, 39, 687-728.

Greenberg, D. L., Rice, H. J., Cooper, J. J., Cabeza, R., Rubin, D. C. \& LaBar, K. S. (2005). Co-activation of the amygdala, hippocampus and inferior frontal gyrus during autobiographical memory retrieval. Neuropsychologia, 43, 659-674.

Jack, A. I. \& Roepstorff, A. (2002). Introspection and cognitive brain mapping: From stimulus-response to script-report. Trends in Cognitive Sciences, 6, 333-339.

Johnson, M. K., Foley, M. A., Suengas, A. G. \& Raye, C. L. (1988). Phenomenal characteristics of memories for perceived and imagined autobiographical events. Journal of Experimental Psychology: General, 117, 371-376.

Johnson, M. K., Hashtroudi, S. \& Lindsay, D. S. (1993). Source monitoring. Psychological Bulletin, 114, 3-28.

McAdams, D. P. (1985). Intimacy: The need to be close. New York: Doubleday.

McCloskey, M., Wible, C. G. \& Cohen, N. J. (1988). Is there a special flashbulb-memory mechanism? Journal of Experimental Psychology: General, 117, 171-181.

McGaugh, J. L. (2003). Memory and emotion: The making of lasting memories. London: Weidenfeld \& Nicolson.

Neisser, U. (2000). Snapshots or benchmarks? Em U. Neisser \& I. E. Hyman (Eds.), Memory observed: Remembering in natural contexts (pp. 68-74). New York: Worth Publishers.

Pillemer, D. B. (1998). Momentous events, vivid memories: How unforgettable moments help us understand the meaning of our lives. Cambridge, MA: Harvard University Press.

Rubin, D. C. (1998). Beginnings of a theory of autobiographical remembering. Em C. P. Thompson, D. J. Herrmann, D. Bruce, J, D. Read, D. G. Payne \& M. P. Toglia (Eds.), Autobiographical memory: Theoretical and applied perspectives (pp. 47-67). Mahwah, NJ: Lawrence Erlbaum Associates.

Rubin, D. C. (2000). The distribution of early childhood memories. Memory, 8, 265-269.

Rubin, D. C. \& Kozin, M. (1984). Vivid memories. Cognition, $16,81-95$.

Rubin, D. C. \& Schulkind, M. D. (1997). Distribution of important and word-cued autobiographical memories in 20-, 35-, and 70year-old adults. Psychology and Aging, 12, 524-535.

Rubin, D. C. \& Siegler, I. C. (2004). Facets of personality and the phenomenology of autobiographical memory. Applied Cognitive Psychology, 18, 913-930.

Rubin, D. C., Rahhal, T. A. \& Poon, L. W. (1998). Things learned in early adulthood are remembered best. Memory \& Cognition, 26, 3-19.

Rubin, D. C., Schrauf, R. W. \& Greenberg, D. L. (2003). Belief and recollection of autobiographical memories. Memory and Cognition, 31, 887-901. 
Schaefer, A. \& Philippot, P. (2005). Selective effects of emotion on the phenomenal characteristics of autobiographical memories. Memory, 13, 148-160.

Singer, J. A. \& Salovey, P. (1993). The remembered self: Emotion and memory in personality. New York: Free Press.

Talarico, J. M. \& Rubin, D. C. (2003). Confidence, not consistency, characterizes flashbulb memories. Psychological Science, 14, 455-461.

Thomsen, D. K. \& Berntsen, D. (2003). Snapshots from therapy: Exploring operationalisations and ways of studying flashbulb memories for private events. Memory, 11, 559-570.

Thorne, A. (2000). Personal memory telling and personality development. Personality and Social Psychology Review, 4, 45-56.

Thorne, A., McLean, K. C. \& Lawrence, A. M. (2004). When remembering is not enough: Reflecting on self-defining memories in late adolescence. Journal of Personality, 72, 513-542.
Tulving, E. (1983). Elements of episodic memory. Oxford: Clarendon Press.

Westbury, C. \& Dennett, D. C. (2000). Mining the past to construct the future: Memory and belief as forms of knowledge. Em D. L. Schacter \& E. Scarry (Eds.), Memory, brain, and belief (pp. 11-32). Cambridge, MA: Harvard University Press.

Wheeler, M. A., Stuss, D. T. \& Tulving, E. (1997). Toward a theory of episodic memory: The frontal lobes and autonoetic consciousness. Psychological Bulletin, 121, 331-354.

Wong, P. \& Watt, L. M. (1991). What types of reminiscence are associated with successful aging? Psychology and Aging, 6, 272-279.

Recebido em 09.02.2007

Primeira decisão editorial em 07.12.2007

Versão final em 26.02.2008

Aceito em 10.04.2008 